\title{
85700 - ASSUNTOS ABORDADOS COM LONGEVOS POR PROFISSIONAIS DA SAÚDE DA FAMÍLIA
}

\author{
Pôster - Gerontologia
}

Cíntia Cristina Sulzbach / SULZBACH, CC / UFSM; Loiva Beatriz Dallepiane / DALLEPIANNE, LB / UFSM

Introdução: A Atenção Primária à Saúde tem papel fundamental na saúde do idoso longevo, sendo que esta população merece atenção especial por se tratar do segmento que mais tem crescido no Brasil1,2. Objetivo: Verificar quais são os assuntos abordados na atenção de idosos longevos por profissionais de Saúde da Família. Métodos: Estudo qualitativo e exploratório com 10 profissionais, utilizando entrevista semi-estruturada, em Estratégias de Saúde da Família no município de Palmeira das Missões-RS. Após transcrição, realizou-se análise temática de conteúdo. O projeto foi aprovado pelo Comitê de Ética em Pesquisa da Universidade Federal de Santa Maria, parecer $\mathrm{n}$ - 1.868.174. Resultados: A maioria dos profissionais afirmou abordar sobre a relação com problemas de saúde dos longevos, como o uso de medicamentos, alimentação, atividade física, prevenção, tratamento e cuidado. Mencionou-se também a importância de uma escuta qualificada, da necessidade do trabalho com a saúde mental, sendo evidenciado o sentimento de solidão dos idosos, da relação com a família, de situações de violência e da demanda por um cuidador ou familiar de referência. Não houve a menção de abordagem considerando a avaliação geriátrica ampla, ou capacidades funcionais, tampouco de cuidados diferenciados ou específicos destinados aos idosos com mais de 80 anos. Conclusões: Percebeu-se que a maioria dos discursos referia-se a uma abordagem biomédica, baseando-se nas queixas. Contudo, o trabalho com longevos na saúde da família demanda por uma abordagem ampliada, destacando-se a importância da educação permanente focada no cuidado e na atenção para esta população. A percepção dos profissionais de saúde é relevante para a qualificação do cuidado aos longevos, uma população que apresenta maior vulnerabilidade, e pode qualificar o trabalho dos profissionais da saúde da família e para a constituição e desenvolvimento de instrumentais teórico-práticos e de linhas de cuidado integrais relacionadas à população com 80 ou mais anos.

Referências: 1. CAMARANO, AA. Envelhecimento da População Brasileira: uma contribuição demográfica. Texto para Discussão no 858. Rio de Janeiro: IPEA, 2002; 2. DA CRUZ, IBM. et al. Prevalência de obesidade em idosos longevos e sua associação com fatores de risco e morbidades cardiovasculares. Revista da Associação Médica Brasileira, São Paulo, v. 50, n. 2, p. 172-177, abr., 2004. 